\title{
Metal (Ni and Bi) coated porous silicon nanostructure, High- performance anode materials for lithium ion batteries with high capacity and stability
}

\author{
Ali A. Ensafi*, Mehdi Mokhtari Abarghoui and Behzad Rezaei \\ Department of Chemistry, Isfahan University of Technology, Isfahan, 84156-83111, Iran
}

\begin{abstract}
\end{abstract}
Herein, metal (nickel and bismuth) nanoparticles are supported on porous silicon flour (PSiF). Then they are proposed as high-performance anode materials for lithium ion battery. In this way, a facile procedure is introduced for the in-situ electroless assembling of nickel and bismuth nanoparticles on PSiF without using any reducing agent. The Metal@PSiF nanostructures with different Metal/Si ratio are prepared through the chemical reduction of the metals ions and oxidation of the surface of $\mathrm{Si}$ atoms, in a solution containing fluoride ions. The composition and morphological properties of the nanostructures are investigated using SEM, XRD, XPS and EDS. Also, galvanostatic charge-discharge and cyclic voltammetry are used to evaluate the electrochemical performance of the proposed anode materials. The synthesized Bi@PSiF nanostructure offers a specific capacity of $3245 \mathrm{mAh} \mathrm{g}^{-1}$ at the $0.1 \mathrm{C}$ rate while the Ni@PSiF shows a specific capacity of $2585 \mathrm{mAh} \mathrm{g}^{-1}$ at the same C-rate. Both nanostructure still retains a specific capacity of about $2000 \mathrm{mAh} \mathrm{g}^{-1}$ after 100 cycles, which is more than five-times larger when it compared with graphite $\left(372 \mathrm{mAh} \mathrm{g}^{-1}\right)$. The obtained results confirm that the new nanostructures are an excellent candidate for anode material in advanced lithiumion batteries with enhanced capacity and excellent columbic efficiency.

*Corresponding author: Fax: +98-31-33912350; Tel.: +98-31-33913269. E-mail: Ensafi@cc.iut.ac.ir; aaensafi@gmail.com 
Keywords: Porous silicon flour; Bismuth nanoparticles; Nickel nanoparticles; Lithiumion battery; Anodic compounds.

\section{Introduction}

Li-ion batteries have been used in energy-storage applications, due to their superior charge storage properties (including high capacity and low self-discharge rates) in comparison with other rechargeable batteries [1]. However, to achieve super-high energy density, advanced electrode materials with high energy storage capacities must be developed to replace traditional $\mathrm{LiCoO}_{2}$ cathode and graphite anode materials [2]. In the case of the anode, considering specific capacities in combination with such parameters as material abundance, cost, and toxicity, aluminum, tin, and silicon seem to be the most promising candidates to replace carbon anodes [3]. Among this electrode materials, silicon is far ahead regarding its gravimetric capacity that is approximately four times higher than capacities of aluminum and tin and about ten times greater than the capacities of traditional graphite anodes [3]. The unmatchable combination of high capacity, attractive chargedischarge profile, silicon availability, low cost and environmental friendliness, makes silicon a very promising anode material. However, silicon still has not been implemented in commercial batteries due to its low electronic conductivity, slow lithium diffusion and the huge (up to $400 \%$ ) volume changes during cycling [4]. Recent studies on $\mathrm{Si}$ nanostructures such as nanowires [5-7], macro- [8-10] and nano-porous materials [11], nanocomposites [12,13], thin films [14,15], nanobelt [16] and nanotube [17] show significant promise in overcoming this issues since these types of nanostructures can provide individual geometries to accommodate the large volumetric expansion and facilitate the lithium ions insertion and extraction into the anode matrix, without mechanical fracture of active materials [18]. 
In this work, in an attempt to improve the electrochemical performance of siliconbased anodes, porous silicon was prepared by metal-assisted chemical etching of commercial silicon powder. Then, nickel and/or bismuth nanoparticles were deposited on the surface of porous silicon flour using a facile electroless approach. The electrochemical evaluations revealed that both of the anode materials (Ni@PSiF and Bi@PSiF) offer higher specific capacity as well as cyclic stability in Li-ion battery in comparison with commercial silicon powder and porous silicon flour.

\section{Experimental}

\subsection{Preparation of PSiF}

Metal-assisted chemical etching of silicon was done according to the literature [19]. Briefly, $5.0 \mathrm{~g}$ of polycrystalline Si powder (325 meshes) was dispersed in $100 \mathrm{~mL}$ of a solution, which consisted of $\mathrm{HF}(5 \mathrm{M})$ and $\mathrm{AgNO}_{3}(5 \mathrm{mM})$. After mild stirring for about 10 min, the Ag nanoparticles were deposited on the surface of silicon microparticles. Then, the remaining $\mathrm{Ag}$ precursors were removed by rinsing three times with distilled water. After that, the Ag-coated silicon powder was dispersed in an etchant solution (100 mL) consisting of $5 \mathrm{M} \mathrm{HF}$ and $0.1 \mathrm{M}$ hydrogen peroxide $\left(\mathrm{H}_{2} \mathrm{O}_{2}\right)$ at $50{ }^{\circ} \mathrm{C}$ for $30 \mathrm{~min}$, to synthesize Ag-coated PSiF. Finally, the Ag nanoparticles completely removed by immersing the Ag-coated PSiF in $5 \mathrm{M}$ nitric acid for $2 \mathrm{~h}$ to obtain the PSiF.

\subsection{Preparation of metal coated PSiF nanostructures}

The detailed mechanism of the galvanic replacement of surface silicon atoms with noble metals has been described in the literature [20]. As can be seen in the following halfreactions, the elemental silicon can act as a reducing agent in the presence of fluoride ions [20]: 


$$
\mathrm{Si}_{(\mathrm{s})}^{0}+6 \mathrm{HF} \rightarrow \mathrm{SiF}_{6}^{2-}+6 \mathrm{H}^{+}+4 \mathrm{e}^{-}
$$$$
\mathrm{M}^{\mathrm{n}+}+\mathrm{ne}^{-} \rightarrow \mathrm{M}_{(\mathrm{s})}^{0}
$$

Where $\mathrm{M}$ denotes any metal (nobler than hydrogen such as copper, gold, bismuth, etc.). In the case of less noble metals such as nickel and cobalt, due to the fact that the redox potential of these metals is negative, hydrogen evolution dominates over the metal displacement. So, the fluoride-containing solution at $\mathrm{pH} 8$ must be used for metal deposition on the silicon surface [21]. Based on the mentioned behavior of silicon in fluoride-containing solutions, we devise a facile wet electroless approach for the preparation of Ni@PSiF and Bi@PSiF nanostructures.

In the case of $\mathrm{Bi} @ \mathrm{PSiF}, 1.0 \mathrm{~g}$ of PSiF ultrasonically dispersed in $100 \mathrm{~mL}$ of $\mathrm{HF}(0.1$ M) solution. Then, $100 \mathrm{~mL}$ of $\mathrm{Bi}\left(\mathrm{NO}_{3}\right)_{3} .5 \mathrm{H}_{2} \mathrm{O}$ with different concentration (4.0, 5.0, 6.0 and $7.0 \mathrm{~g} / \mathrm{L}$ ) was added with vigorous stirring. After about $30 \mathrm{~min}$, the obtaining nanostructures were washed three-time with water and dried at room temperature for $12 \mathrm{~h}$. For the Ni@PSiF preparation, $1.0 \mathrm{~g}$ of PSiF was dispersed in a solution containing $0.1 \mathrm{M}$ of ammonium fluoride (pH 8). After that, $100 \mathrm{~mL}$ of $\mathrm{NiSO}_{4} \cdot 6 \mathrm{H}_{2} \mathrm{O}$ with different concentration $(4.5,9.0,13.5$ and $18.0 \mathrm{~g} / \mathrm{L})$ was added to the stirring mixture, drop by drop. After about $1 \mathrm{~h}$, the resulting nanostructures were filtered and dried at room temperature.

\subsection{Materials Characterization and Electrochemical Measurements}

The morphology and size of the synthesized nanocomposites were investigated by a field emission scanning electron microscope (FE-SEM, Hitachi S4160, Tokyo, Japan) and a transmission electron microscope (Philips/FEI CM200 operating at $200 \mathrm{kV}$ ). To confirm the synthesis of the nanocomposites, a Bruker $\mathrm{D}_{8} /$ Advance $\mathrm{X}$-ray diffractometer with $\mathrm{Cu}-\mathrm{K}_{\alpha}$ radiation $(\lambda=1.5418 \AA)$ was used. The chemical composition of the nanocomposite was analyzed based on obtained EDS spectra (Philips XLS instrument, The 

XR3 E2-(VG Microtech) with twin anode X-ray source was used for the XPS analysis. Electrochemical evaluations including cyclic voltammetry and galvanostatic chargedischarge tests were done using an Ivium potentiostat/galvanostat electrochemical analyzer (pocket STAT Model) with a homemade two electrode electrochemical cell (similar to Swagelok-type cells) between cut-off potentials of 0.01 and $1.50 \mathrm{~V}$. A typical working electrode (anode) was prepared by hand mixing of $80 \mathrm{wt} . \%$ active material (silicon-based nanocomposites) with $10 \mathrm{wt} . \%$ PVDF binder and $10 \mathrm{wt} . \%$ acetylene black in N-methyl-2material was composed of silicon only.

\section{Results and discussion}

\subsection{Characterization of the Metal@PSiF nanostructures}

The elemental analysis of the different nanostructures of Ni@PSiF and Bi@PSiF were carried out using the EDS technique. The results (Table 1 and 2) show that increasing the concentration of nickel or bismuth precursor's the solution cause increasing the metal content of Metal@PSiF nanostructures. Figs. 1A and 1B show the EDS spectra of $\mathrm{Ni@PSiF} \mathrm{(sample} \mathrm{3)} \mathrm{and} \mathrm{Bi} @ \mathrm{PSiF}$ (sample 7) and their chemical compositions as well as their elemental mappings. The EDS spectra of Ni@PSiF demonstrates the presence of 
silicon and nickel, while EDS spectra of $\mathrm{Bi} @ \mathrm{PSiF}$ confirms the presence of bismuth and silicon. The above results confirm that both nanostructures (with different metal/Si ratios) were successfully synthesized. "Here Tables $1 \&$ 2"

Figs. 1C and 1D show the FE-SEM images of Ni@PSiF (sample 3) and Bi@PSiF (sample 7) nanostructures. As can be seen, the metal (Ni and $\mathrm{Bi}$ ) nanoparticles have been uniformly supported on the surface of PSiF with the diameter range of 50 to $80 \mathrm{~nm}$. The XRD patterns of Ni@PSiF and Bi@PSiF were also recorded over the $2 \theta$ ranges of $20-100^{\circ}$ (Fig. 2 A). The characteristics peaks of PSiF at $2 \theta$ of $28.4^{0}, 47.2^{\circ}, 56.2^{\circ}, 69.1^{\circ}, 76.5^{\circ}, 88.2^{\circ}$ and $94.8^{\circ}$ which can be assigned to the planes of $\mathrm{Si}$ (111), Si (220), Si (311), Si (400), Si (331), Si (442) and Si (511), respectively [22] are presented in the XRD patterns PSiF (curve a), Ni@PSiF (curve b) and Bi@PSiF (curve c) nanostructures. Also, the XRD 
exhibited two asymmetrical peaks at 166.1 and 171.7 corresponds to the spine-orbit split states of $\mathrm{Bi} 4 \mathrm{f}^{7 / 2}$ and $4 \mathrm{f}^{5 / 2}$ (Fig 3 D) while the Ni@PSiF XPS survey exhibited the characteristic peaks of Ni nanoparticles [26] "Here Figure 3"

Before metal coating, the Brunauer-Emmett-Teller (BET) technique was used for determination of the specific surface area of PSiF based on nitrogen adsorption-desorption $\left(38.93 \mathrm{~m}^{2} \mathrm{~g}^{-1}\right)$ indicates the efficient loading of metal nanoparticles on the surface of PSiF.

\subsection{Electrochemical performance of Metal@PSiF nanostructures}

First of all, the cyclic voltammograms of different silicon-based anodes were performed at $0.01-1.50 \mathrm{~V} v s . \mathrm{Li} / \mathrm{Li}^{+}$as a potential range with a scan rate of $0.1 \mathrm{mV} / \mathrm{s}$. The obtained results (Fig. 4) revealed that the shapes of the voltammograms are consistent with the previously reported results by other researchers for nanostructured silicon anode materials [27]. As can be seen in Fig. 3, for all anode materials, significant lithiation due to the formation of $\mathrm{Li}_{\mathrm{x}} \mathrm{Si}_{\mathrm{y}}$ occurs at the potentials of below $0.30 \mathrm{~V}$, while de-lithiation (the de-alloying of the lithium ion from the $\mathrm{Li}_{\mathrm{x}} \mathrm{Si}_{\mathrm{y}}$ structure) is mostly completed before the voltage reaches the value of $0.70 \mathrm{~V}$ [5]. As shown in Figs. 4A and 4B, although the observed lithiation and de-lithiation potentials of PSiF anode were almost equal to that of non-porous silicon anode but the integral area of the cyclic voltammogram loop was higher in the case of PSiF anode. This is mainly ascribed to the porous structure of silicon 
and consequently facilitated lithium ions insertion and extraction into the anode matrix.

177 The cyclic voltammograms of Ni@PSiF and Bi@PSiF anode materials were also recorded (Figs. 4C and 4D). The higher conductivity of Metal@PSiF anodes in comparison with PSiF leads to the higher lithiation and de-lithiation peak intensity and integral area of cyclic voltammograms [27]. "Here Fig. 4"

For further study, the galvanostatic charge-discharge tests of $\mathrm{Ni@PSiF}$ and $\mathrm{Bi} @ \mathrm{PSiF}$ anode materials were conducted in a potential range of 0.01 to $1.50 \mathrm{~V} v s . \mathrm{Li} / \mathrm{Li}^{+}$ at the current density of $0.8 \mathrm{C}$ and compared with that of non-porous silicon and PSiF anodes. Fig. 5 shows the second charge-discharge cycles of the different anode materials. The results indicate that the specific capacity of Bi@PSiF (1905 mAh $\left.\mathrm{g}^{-1}\right)$ and $\mathrm{Ni@PSiF}$ (1548 $\left.\mathrm{mAh} \mathrm{g}^{-1}\right)$ anodes are higher than for PSiF (1224 $\left.\mathrm{mAh} \mathrm{g}^{-1}\right)$ and for non-porous silicon (653 mAh g ${ }^{-1}$ ) anodes. The higher capacity of Metal@PSiF, which is in agreement with the obtained results by cyclic voltammetry, can be ascribed to the high specific surface area and the higher conductivity of Metal@PSiF. "Here Fig. 5"

The influence of metal content of Metal@PSiF nanostructures on the specific capacity of prepared anodes was also examined. In this way, galvanostatic chargedischarge curves of the different Ni@PSiF (samples 1-4) and Bi@PSiF (samples 5-8) anodes were recorded in the potential ranges of 0.01 and $1.50 \mathrm{~V}$ vs. $\mathrm{Li} / \mathrm{Li}^{+}$at the current density of 0.8 C. As can be seen in Table 3, with increasing the metal content, the specific capacity initially increases and then decreases. The former is believed to be due to an enhancement in the electronic contact of the PSiF with the current collector, which reduces the pulverization of the anodes during the lithiation and de-lithiation process. The latter results can be ascribed to the decreasing of the active material $(\mathrm{Si})$ content of the prepared anodes [28]. Based on the obtained results (Table 3) Ni@PSiF with a nickel content of 

the rest of the study. "Here Table 3"

For further study, the charge-discharge profiles of the Metal@PSiF nanostructures at different $\mathrm{C}$ rates were recorded in the potential ranges of 0.01 and $1.50 \mathrm{~V}$. Figs. $6 \mathrm{~A}$ and 6C show the charge-discharge curves of the $\mathrm{Ni} @ \mathrm{PSiF}$ and $\mathrm{Bi} @ \mathrm{PSiF}$ anode materials from $0.2 \mathrm{C}$ to $3.2 \mathrm{C}$ rate while Figs. $6 \mathrm{~B}$ and $6 \mathrm{D}$ illustrate the variation of the specific capacity $v s$. the $\mathrm{C}$ rate. The obtained results revealed that with increasing the $\mathrm{C}$ rate the lithiation and de-lithiation capacities of the proposed anodes decrease. This behavior is due to the decreasing in the degree of utilization of the anode material active sites at higher $\mathrm{C}$ rates. Also, at higher $\mathrm{C}$ rates, due to an inadequate time for the lithium ions to interact with the active sites of silicon, the anode-electrolyte interaction would be limited. Thus, the alloying and de-alloying of the lithium ions will decrease due to the diffusion polarization

\section{[29]. "Here Fig. 6"}

To evaluate the effect of porous structure formation and metal nanoparticle deposition on the cyclic performance of the silicon-based anodes, the consecutive chargedischarge curves of the non-porous silicon, PSiF, Ni@PSiF and Bi@PSiF anodes were recorded in the potential ranges of 0.01 and $1.50 \mathrm{~V}$. Fig. 7 illustrates the specific capacity of the different anode materials at $0.1 \mathrm{C}$ rate upon the cycle number. As can be seen, the PSiF anode retains a capacity of $1566 \mathrm{mAh} \mathrm{g}^{-1}$ after 50 cycles, while the non-porous silicon anode maintains a capacity of $693 \mathrm{mAh} \mathrm{g}^{-1}$ after only 25 cycles. The higher capacity and the lower fading rates of PSiF anode in comparison with non-porous silicon anode can be attributed to its porous structure and consequently the higher strain and destruction as well as pulverization of active materials due to alloying and de-alloying of the lithium ions. 

also studied. A remarkable improvement in the specific capacity and cyclic stability, as well as coulombic efficiency, was observed when $\mathrm{Ni}$ and $\mathrm{Bi}$ nanoparticles were deposited on the surface of PSiF anodes. The obtained cyclic stability and coulombic efficiency can be ascribed to the large surface area of the conductive metal nanoparticles coating, and thus the large contact area between the $\mathrm{PSiF}$ and $\mathrm{Ni}$ or $\mathrm{Bi}$, allowed uniform $\mathrm{Li}$ insertion and extraction within the PSiF [30]. Moreover, Ni@PSiF shows much superior cycling stability (the capacitance retention of $73 \%$ after 100 cycles) over other Bi@PSiF (the capacitance retention of $64 \%$ after 100 cycles). This is ascribed to the higher binding and buffering effects of the Ni nanoparticles layer that accommodate the large volume change during cycling [31]. As shown in Fig. 7A, after 100 cycles, the Ni@PSiF and Bi@PSiF anodes exhibited a capacity of about 1873 and $2069 \mathrm{mAh} \mathrm{g}^{-1}$, respectively which is about five times larger compared with that of graphite anode $\left(372 \mathrm{mAh} \mathrm{g}^{-1}\right)$. Long term stability and charge storage capacity comparison of the different silicon nanostructures for Li-ion batteries application $v s$. our proposed anode materials are given in Table 4 [32-38]. Also, the structure changes of the electrode materials after charge/discharge cycling have been investigated using XRD and FE-SEM. As can be seen in Fig 7B, after 50 cycles, the XRD pattern of PSiF does not show any characteristic peaks for the silicon planes, which reveals that the active material becomes from crystalline to amorphous. Also, after 100 cycles, the crystalline Si peaks of Ni@PSiF (curve b) and Bi@PSiF (curve c) completely disappeared (as a result of the crystalline to the amorphous transformation of silicon) and only crystalline peaks of metal nanoparticles were seen. Other studies confirm that crystalline silicon becomes amorphous during lithium insertion and extraction [39]. FE-SEM images of Ni@PSiF (Fig 7C) and Bi@PSiF (Fig 7D) after 100 cycles also revealed that nano metal coated PSiF possess good structure stability during charge/discharge process. 


\section{Conclusion}

251

252

In this paper, a facile electroless approach was introduced for the synthesis of the Ni@PSiF and Bi@PSiF nanostructures. The prepared nanostructures were characterized with different techniques and used as anode materials for lithium ion batteries. The electrochemical evaluations indicate that $\mathrm{Ni}$ and $\mathrm{Bi}$ nanoparticles improve the specific capacity and cyclic stability as well as columbic efficiency of the PSiF anodes. The key for these superior performances is believed to lie in the high surface area of PSiF and the uniform conductive metal nanoparticles coating of the PSiF surface. Ease of preparation, combined with high electrochemical performance and silicon abundance, implies that the proposed nanostructures have potential applications as an anode electrode material for lithium ion batteries.

\section{Acknowledgments}

The authors wish to thank Iran National Science Foundation for financial support of this work.

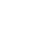

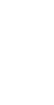

.

Of this work.




\section{References}

274 [1] Dan Li, Hongyan He, Ximin Wu, Mingqi Li, J. Alloys and Compounds, 682, (2016) 759-765.

276

[2] T. Cetinkaya, M. Tokur, S. Ozcan, M. Uysal, H. Akbulut, Int. J. Hydrogen. Energy, 41

277 (2016) 6945-6953.

278

[3] Y. Zhao, X. Li, L. Dong, B Yan, H. Shan, D. Li, X. Sun, Int. J. Hydrogen. Energy, 40 (2015) 14338-14344.

[4] S.D. Beattie, D. Larcher, M. Morcrette, B. Simon, J.M. Tarascon, J. Electrochem. Soc. 155 (2008) A158-A163.

282

[5] C.K. Chan, H.I. Peng, G. Liu, K. McIlwraith, X.F. Zhang, R.A. Huggins, Y. Cui, Nature Nanotech. 3 (2008) 31-35.

[6] H. Kim, J. Cho, Nano Lett. 8 (2008) 3688-3691.

[7] Umesh Rizal, Bhabani S. Swain, Bibhu P. Swain, J. Alloys and Compounds, 664 (2016) 453-459.

[8] Y. Yu, L. Gu, C.B. Zhu, S. Tsukimoto, P.A.V. Aken, J. Maier, Adv. Mater. 22 (2010) $2247-2250$.

[9] H. Kim, B. Han, J. Choo, Angew. Chem. Int. Ed. 47 (2008) 10151-10154.

[10] H.C. Shin, J.A, Corno, J.L. Gole, M.L. Liu, J. Power. Sources 139 (2005) 314-320.

291

[11] Y. Zheng, J. Yang, J.L. Wang, Y.N. Nu, Electrochim. Acta 52 (2007) 5863-5867.

292

[12] Fengjuan Miao, Bairui Tao, Paul K. Chu, J. Alloys and Compounds, 619 (2015) 748753.

[13] Y. Qin, Q. Li, J. Xu, X. Wang, G. Zhao, C. Liu, X. Yan, Y. Long, S. Yan, S. Li, Electrochim Acta 224 (2017) 90-95.

297 [14] Manwen Yao, Zhen Su, Pei Zou, Jianwen Chen, Fei Li, Qian Feng, Xi Yao, J. Alloys and Compounds, 690 (2017) 249-255. 
[15] W. Xu, N.L Canfield, D.Y. Wang, J. Xiao, Z.M. Nie, X.A. Li, W.D. Bennett, C.C. Bonham, J.G. Zhang, J. Electrochem. Soc. 157 (2010) A765-A769.

[17] W. Wang, P.N. Kumta, ACS Nano 4 (2010) 2233-2241.

[18] R. Teki, M.K. Datta, R. Krishnan, T.C. Parker, T.M. Lu, P.N. Kumta, N. Koratkar, Small 5 (2009) 2236-2242.

305

[20] L. Magagnin, R. Maboudian, C. Carraro, J. Phys. Chem. B 106 (2002) 401-407.

[21] P. Gorostiza, M.A. Kulandainathan, R. Díaz, F. Sanz, P. Allongue, J.R. Morante, J. Electrochem. Soc. 147 (2000) 1026-1030.

[22] J.M. Westra, V. Vavruňková, P. Šutta, R.A.C.M.M. Swaaij, M. Zeman, Energy Procedia 2 (2010) 235-241.

[23] E.V. Gopalan, K.A. Malini, G.S. kumar, T.N. Narayanan, P.A. Joy, I.A. Al-Omari, D.S. Kumar, Y. Yoshida, M.R. Anantharaman, Nanoscale Res. Lett. 5 (2010) 889-897.

[24] R. Devasenathipathy, V. Mani, S.M. Chen, Talanta 124 (2014) 43-41.

[25] A.A. Ensafi, M. Jafari-Asl, B. Rezaei, M.M Abarghoui, H. Farrokhpour, J. Power Sources $282(2015) 452$.

[26] A. P. Singh, N Kodan, A. Dey, S. Krishnamurthy, B. R. Mehta, Int. J. Hydrogen. Energy 40 (2015) 4311-4319.

[27] C. Li, P. Zhang, Z. Jiang, Electrochim. Acta 161 (2015) 408-412.

[28] T. Cetinkaya, M. Uysal, H. Akbulut, Appl. Surf. Sci. 334 (2015) 94-101.

[29] M. Ge, Y. Lu, P. Ercius, J. Rong, X. Fang, M. Mecklenburg, C. Zhou, Nano Lett. 14 (2014) 261-268.

[30] J.W. Kim, J.H. Ryu, K.T. Lee, S.M. Oh, J. Power. Sources 147 (2005) 227-233. 

A 2 (2014) 6396-6401.

[32] Q. Wang, L. Han, X. Zhang, J. Li, X. Zhou, Z. Lei, Mater. Lett. 185 (2016) 558-560. (2013) 174-181.

[36] X. L. Li, P. Meduri, X. L. Chen, W. Qi, M. H. Engelhard, W. Xu, F. Ding, J. Xiao, W.

Wang, C. M. Wang, J.-G. Zhang and J. Liu, J. Mater. Chem. 22 (2012) 11014-11017.

[37] H. Tian, X. Tan, F. Xin, C. Wang, W. Han, Nano Energy 11 (2015) 490-499. Acta 208 (2016) 174-179. 
Table 1. The initial concentration of nickel precursor for preparation of different Ni@PSiF nanostructures and their corresponding chemical composition (determined by EDS technique)

\begin{tabular}{|c|c|c|c|c|c|}
\hline Sample & $\mathrm{NiSO}_{4} \cdot 6 \mathrm{H}_{2} \mathrm{O} \mathrm{g} / \mathrm{L}$ & Element & Line & Wt. \% & \\
\hline \multirow[t]{3}{*}{1} & 4.5 & $\mathrm{Si}$ & $\mathrm{K} \alpha$ & 94.66 & \\
\hline & & $\mathrm{Ni}$ & $\mathrm{K} \alpha$ & 5.34 & \\
\hline & & & & 100 & Total \\
\hline \multirow[t]{3}{*}{2} & 9.0 & $\mathrm{Si}$ & $\mathrm{K} \alpha$ & 90.09 & \\
\hline & & $\mathrm{Ni}$ & $\mathrm{K} \alpha$ & 9.91 & \\
\hline & & & & 100 & Total \\
\hline \multirow[t]{3}{*}{3} & 13.5 & $\mathrm{Si}$ & $\mathrm{K} \alpha$ & 85.18 & \\
\hline & & $\mathrm{Ni}$ & $\mathrm{K} \alpha$ & 14.82 & \\
\hline & & & & 100 & Total \\
\hline \multirow[t]{3}{*}{4} & 18.0 & $\mathrm{Si}$ & $\mathrm{K} \alpha$ & 81.77 & \\
\hline & & $\mathrm{Ni}$ & $\mathrm{K} \alpha$ & 18.23 & \\
\hline & & & & 100 & Total \\
\hline
\end{tabular}


362

363

364

\begin{tabular}{|c|c|c|c|c|c|}
\hline Sample & $\mathrm{Bi}\left(\mathrm{NO}_{3}\right)_{2} .5 \mathrm{H}_{2} \mathrm{O} \mathrm{g} / \mathrm{L}$ & Element & Line & Wt. \% & \\
\hline \multirow[t]{3}{*}{1} & 4.0 & $\mathrm{Si}$ & $\mathrm{K} \alpha$ & 76.93 & \\
\hline & & $\mathrm{Bi}$ & $\mathrm{L} \alpha$ & 23.07 & \\
\hline & & & & 100 & Total \\
\hline \multirow[t]{3}{*}{2} & 5.0 & $\mathrm{Si}$ & $\mathrm{Ka}$ & 72.59 & \\
\hline & & $\mathrm{Bi}$ & $\mathrm{L} \alpha$ & 27.41 & \\
\hline & & & & 100 & Total \\
\hline \multirow[t]{3}{*}{3} & 6.0 & $\mathrm{Si}$ & $\mathrm{K} \alpha$ & 68.76 & \\
\hline & & $\mathrm{Bi}$ & $\mathrm{L} \alpha$ & 31.24 & \\
\hline & & & & 100 & Total \\
\hline \multirow[t]{3}{*}{4} & 7.0 & $\mathrm{Si}$ & $\mathrm{K} \alpha$ & 65.14 & \\
\hline & & $\mathrm{Bi}$ & $\mathrm{L} \alpha$ & 34.86 & \\
\hline & & & & 100 & Total \\
\hline
\end{tabular}

Table 2. The initial concentration of bismuth precursor for preparation of different $\mathrm{Bi} @ \mathrm{PSiF}$ nanostructures and their corresponding chemical composition (determined by EDS technique).

365 
Table 3. The $\mathrm{Ni}$ or $\mathrm{Bi}$ content of the different anode materials and their corresponding specific capacity at the current density of $0.8 \mathrm{C}$.

\begin{tabular}{cccccc}
\hline $\begin{array}{c}\text { Anode } \\
\text { material }\end{array}$ & Ni content & $\begin{array}{c}\text { Capacity } \\
\left(\mathrm{mAh} \mathrm{g}^{-1}\right)\end{array}$ & $\begin{array}{c}\text { Anode } \\
\text { material }\end{array}$ & $\begin{array}{c}\text { Bi content } \\
\text { Wt.\% }\end{array}$ & $\begin{array}{c}\text { Capacity } \\
\left(\mathrm{mAh} \mathrm{g}^{-1}\right)\end{array}$ \\
\hline 1 & 5.34 & 1275 & 5 & 23.07 & 1338 \\
2 & 9.91 & 1380 & 6 & 27.41 & 1547 \\
3 & 14.82 & 1548 & 7 & 31.24 & 1905 \\
4 & 18.23 & 1506 & 8 & 34.86 & 1803 \\
\hline
\end{tabular}

379

380

381

382

383

384

385

386

387

388

389

390 
391 Table 4. Comparison of the capacity observed and columbic efficiency in the present work

392 with that of reported silicon-based anode materials for $\mathrm{Li}$-ion batteries $\left(1 \mathrm{C}=4000 \mathrm{mAh} \mathrm{g}^{-1}\right)$.

\begin{tabular}{lccccc}
\hline Anode materials & $\begin{array}{c}\text { Columbic } \\
\text { efficiency }(\%)\end{array}$ & Capacity After Cycles & $\begin{array}{c}\text { Current density } \\
\left(\mathrm{mAh} \mathrm{g}^{-1}\right)\end{array}$ & Cycle & Reference \\
& & (C) & number &
\end{tabular}

Ag deposited 3D

99

755

0.025

50

[32]

porous $\mathrm{Si}$
Amorphous
carbon coated
prickle like $\mathrm{Si}$

96

1125

$0.1 \mathrm{C}$

100

Porous nano-

99

1500

$1 \mathrm{C}$

50

Si@C@RGO

Mesoporous

98

1200

$0.05 \mathrm{C}$

50

Si@C

Hollow porous

97

700

1C

50

$\mathrm{Si} / \mathrm{C}$

Micro-sized

96

600

$0.125 \mathrm{C}$

300

nano-porous

$\mathrm{Si} / \mathrm{C}$

Porous

97

2043

0.075

100

silicon/pyrolyzed

polyacrylonitrile

Ni@PSiF

97

1873

$0.1 \mathrm{C}$

100

This work

Bi@PSiF

98

2069

$0.1 \mathrm{C}$

100

This work 


\section{Legend for the figures:}

Figure 1. EDS spectrum of $\mathrm{Ni} @ \mathrm{PSiF}(\mathrm{A})$, and $\mathrm{Bi} @ \mathrm{PSiF}(\mathrm{B})$ nanostructures and their corresponding elemental mapping; FE-SEM images of Ni@PSiF (C), and Bi@PSiF (D) nanostructures.

Figure 2. XRD patterns of PSiF (curve a), Ni@PSiF (curve b), and Bi@PSiF nanostructures (curve c) in the $2 \theta$ ranges of $20-100^{\circ}$ (A); TEM images of Ni@PSiF (B), and Bi@PSiF (C) nanostructures.

Figure 3. A): Survey XPS data for Ni@PSiF and Bi@PSiF; B): High resolution XPS of Si (2p); C: Ni (3p) and Bi (4f).

Figure 4. Cyclic voltammograms Si (A), PSiF (B), Ni@PSiF (C) and Bi@PSiF at a scan rate of $0.1 \mathrm{mV} \mathrm{s}^{-1}$.

Figure 5. Charge-discharge curves of Si (A), PSiF (B), Ni@PSiF (C) and Bi@PSiF at a rate of $0.8 \mathrm{C}$.

Figure 6. Charge-discharge curves of $\mathrm{Ni} @ \mathrm{PSiF}(\mathrm{A})$ and $\mathrm{Bi} @ \mathrm{PSiF}(\mathrm{C})$ at various $\mathrm{C}$ rates from 0.2 to 3.2 and variation of the specific capacity of $\mathrm{Ni} @ \mathrm{PSiF}(\mathrm{B})$ and $\mathrm{Bi} @ \mathrm{PSiF}(\mathrm{D}) v s$. the $\mathrm{C}$ rates.

Figure 7. Capacity retention and coulombic efficiency of different anode materials vs. the cycle numbers at a rate of $0.1 \mathrm{C}(\mathrm{A})$; XRD patterns of PSiF after 50 cycles (curve a), Ni@PSiF after 100 cycles (curve b) and Bi@PSiF after 100 cycles (curve c) in the $2 \theta$ ranges of 20-60 (B); FE-SEM images of $\mathrm{Ni@PSiF} \mathrm{(C),} \mathrm{and} \mathrm{Bi@PSiF} \mathrm{(D)} \mathrm{nanostructures}$ after 100 cycles. 
$6 \mathrm{~F}_{\text {(aq) }}^{-}+\mathrm{Si} \rightarrow \mathrm{SiF}_{6}^{2-}$ (aq) $+4 \mathrm{e}^{-}$

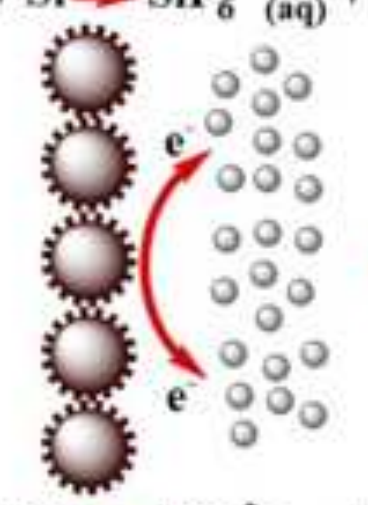

$$
6 \mathrm{~F}_{\text {(aq) }}+\mathrm{Si} \rightarrow-\mathrm{SiF}_{6}^{2-}{ }_{\text {(aq) }}+4 \mathrm{e}^{-}
$$

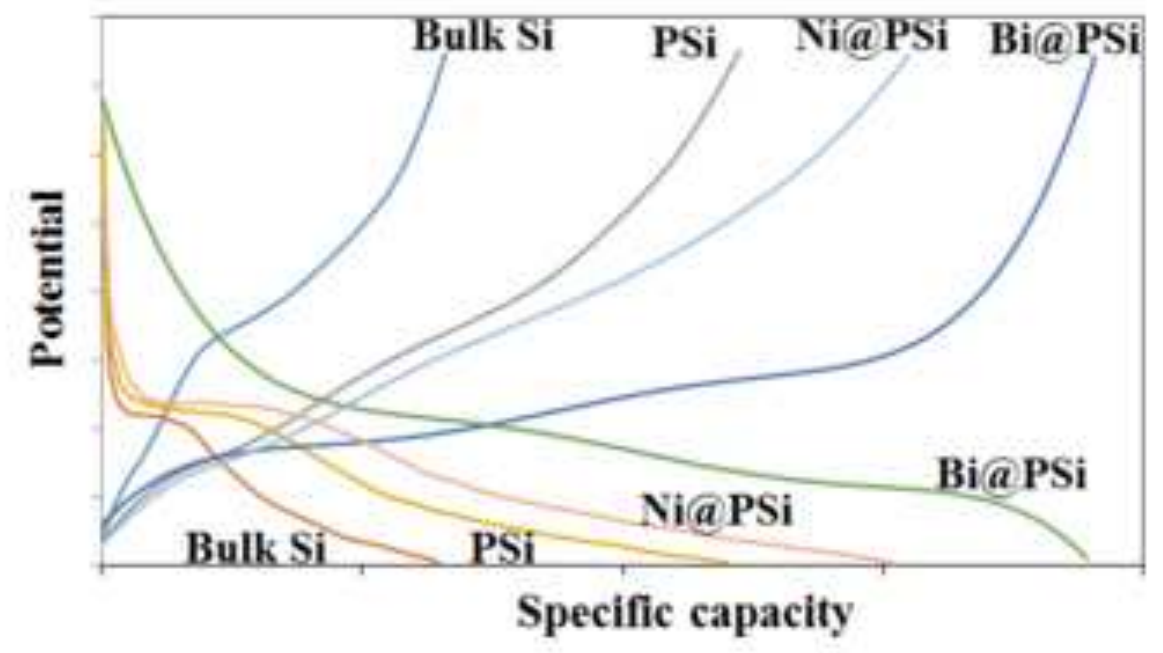

o Metal $\left(\mathrm{Ni}^{2+}\right.$ or $\left.\mathrm{Bi}^{3+}\right)$ ions $\bullet$ Metal nanoparticles

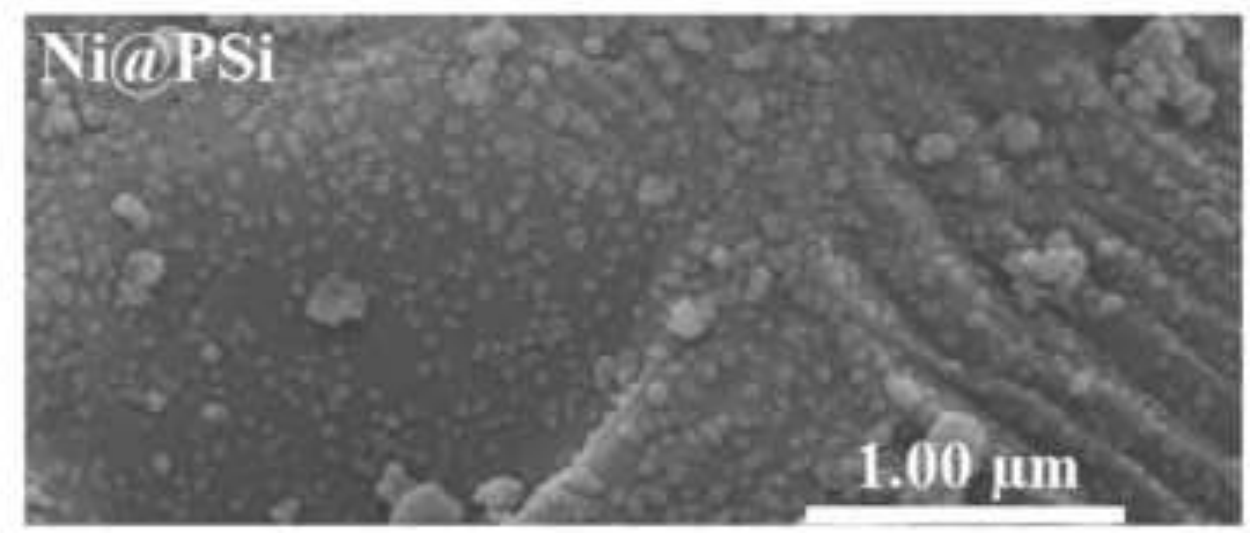

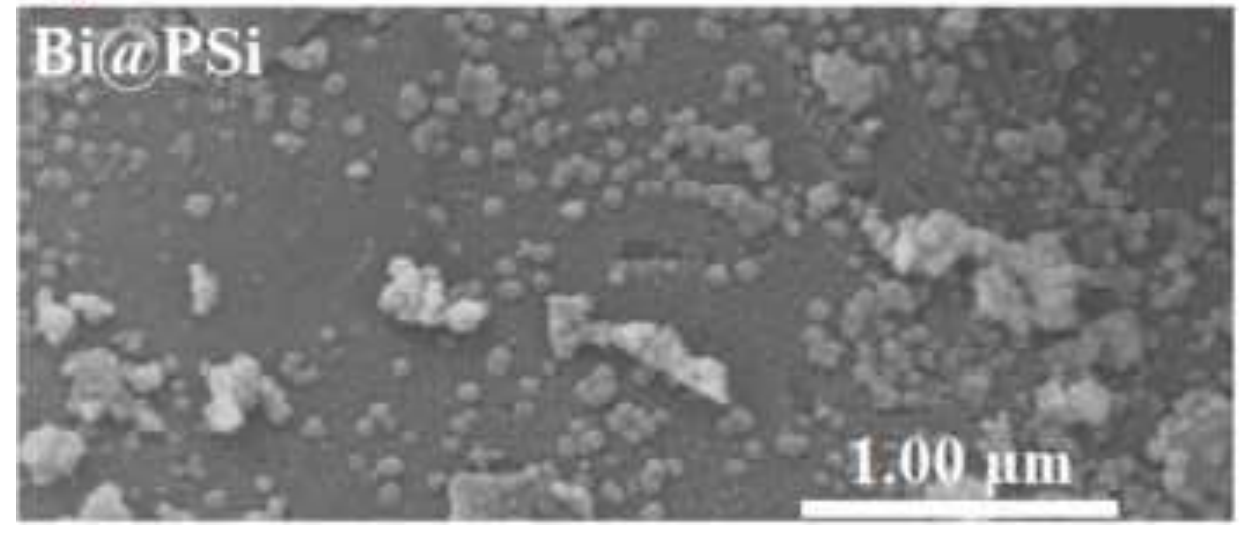



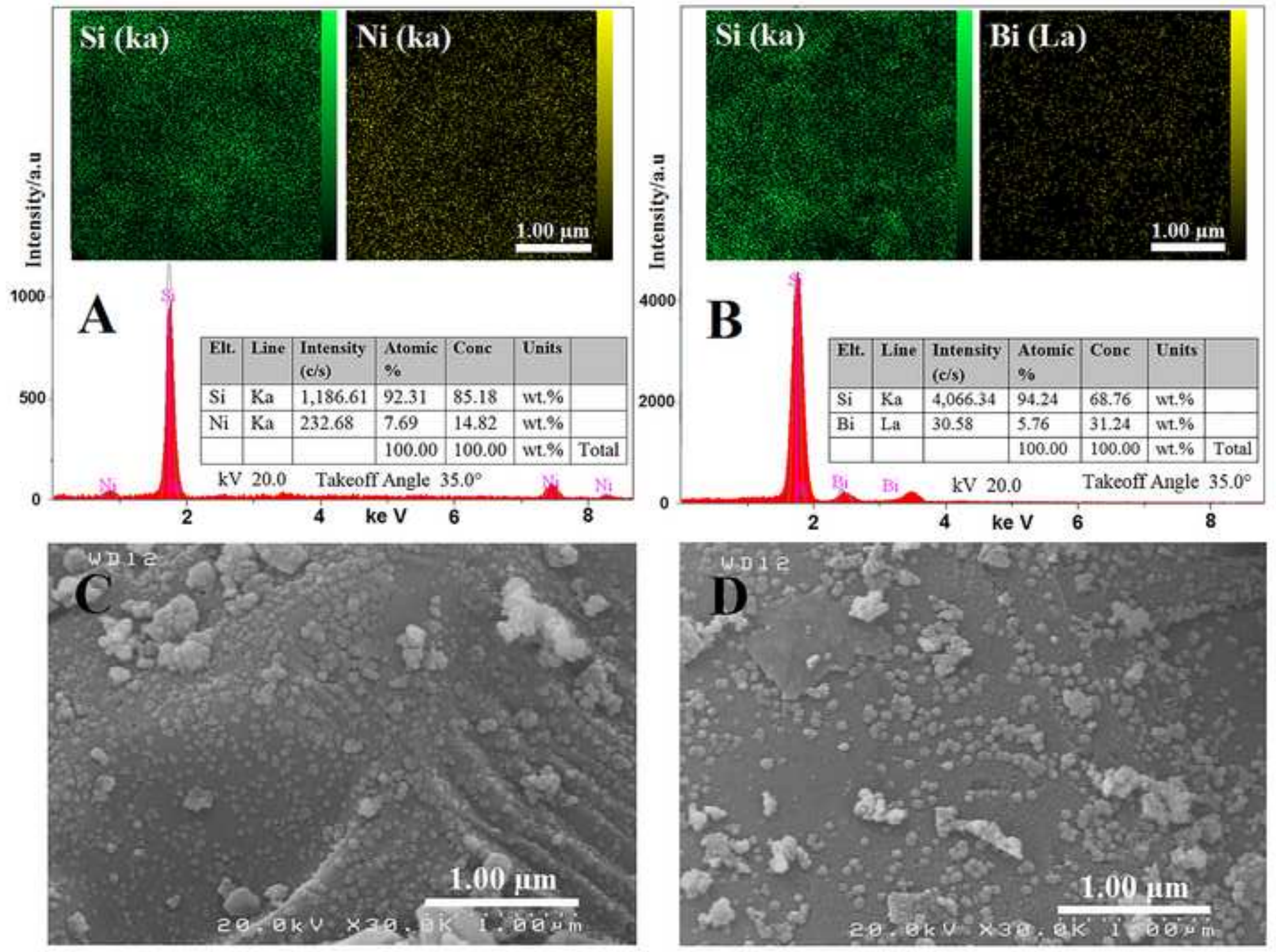


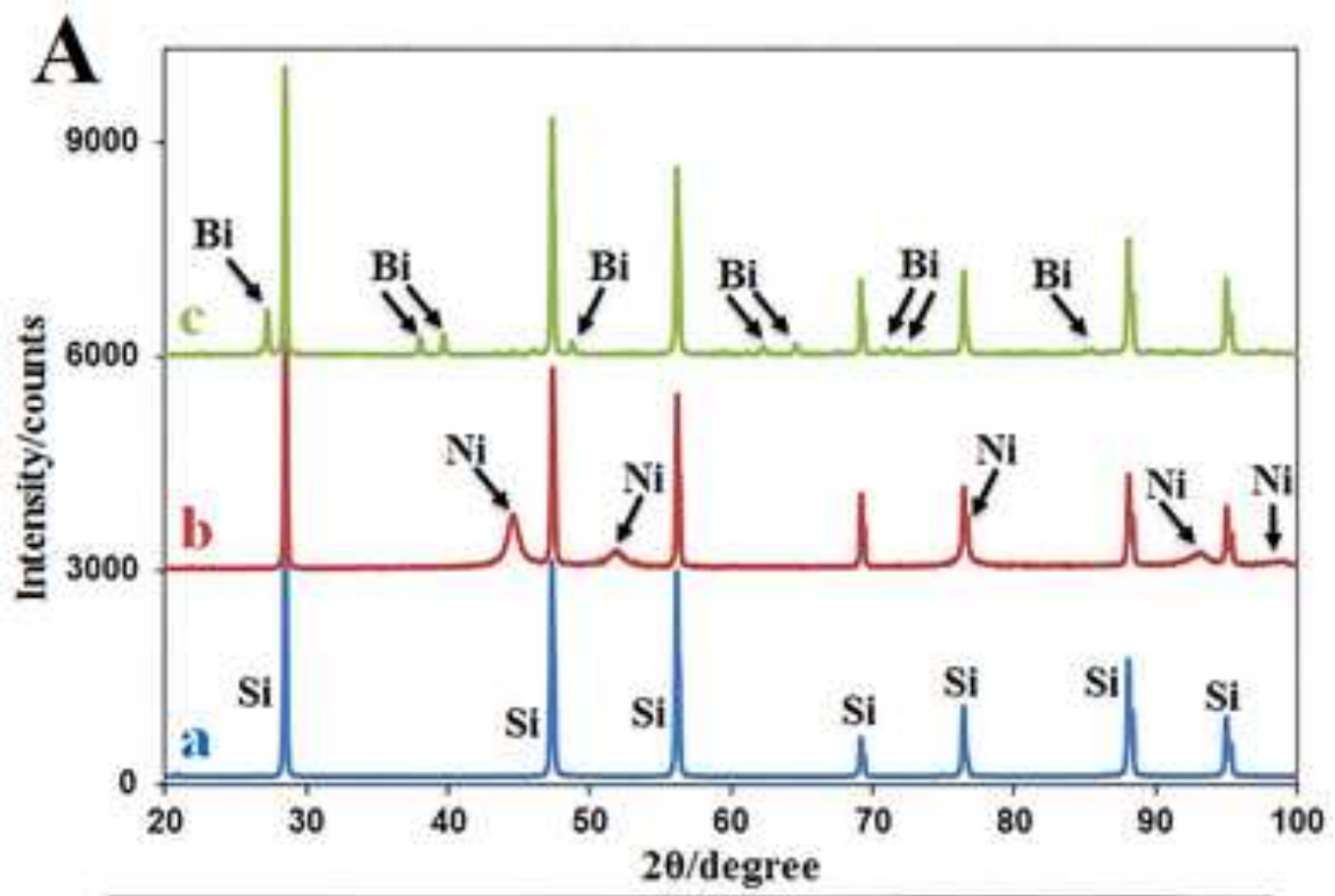

B

C 

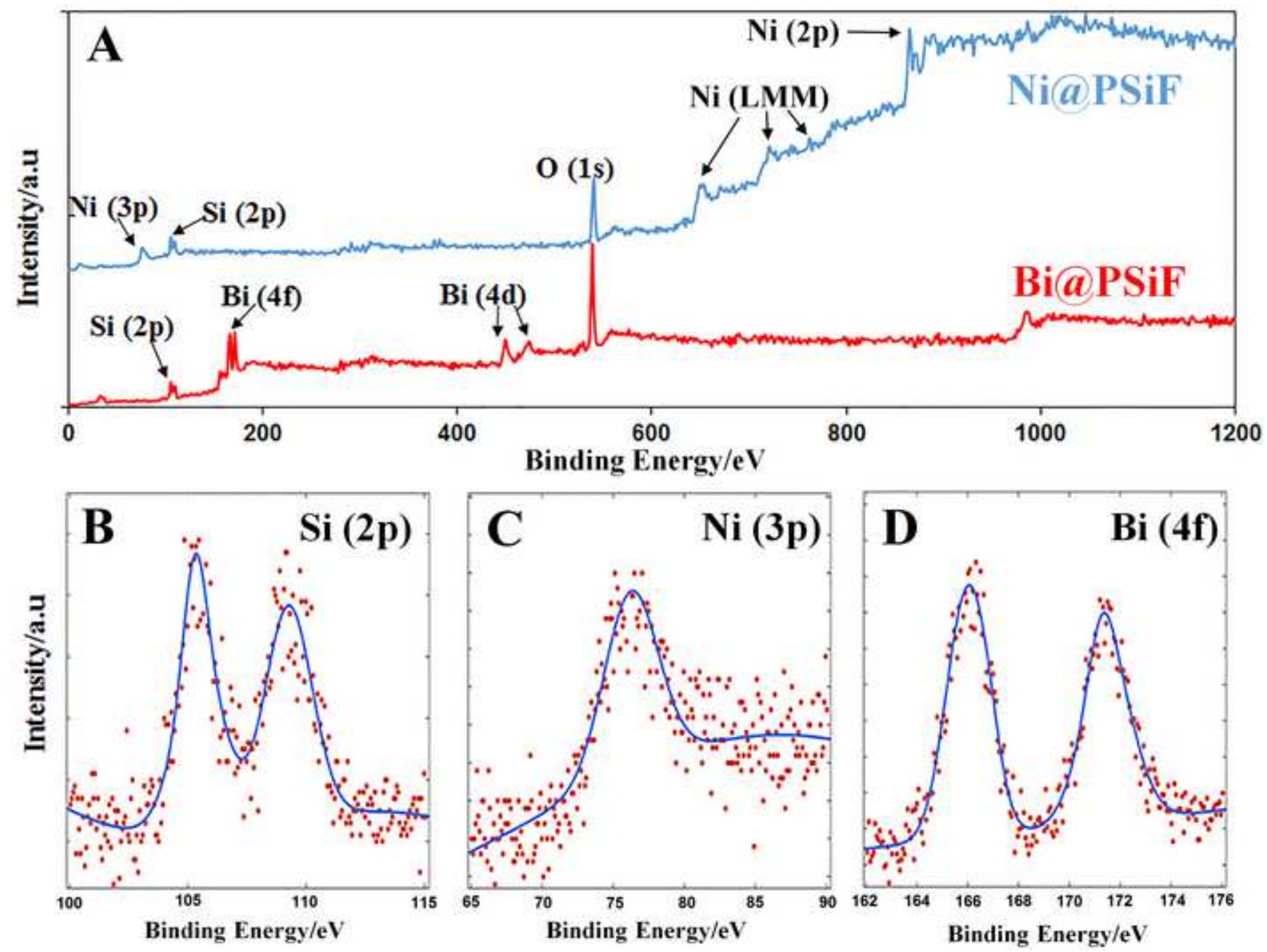

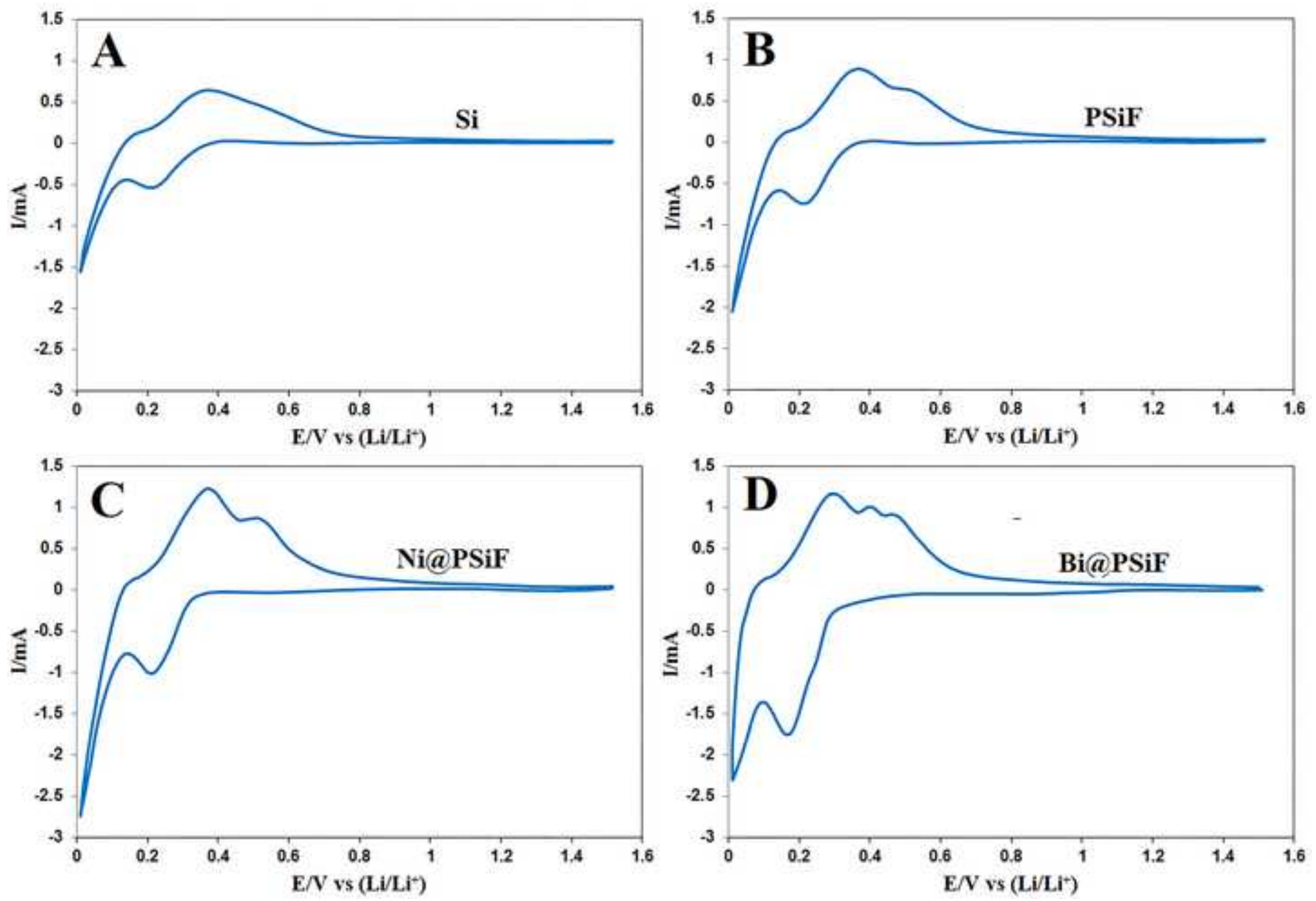

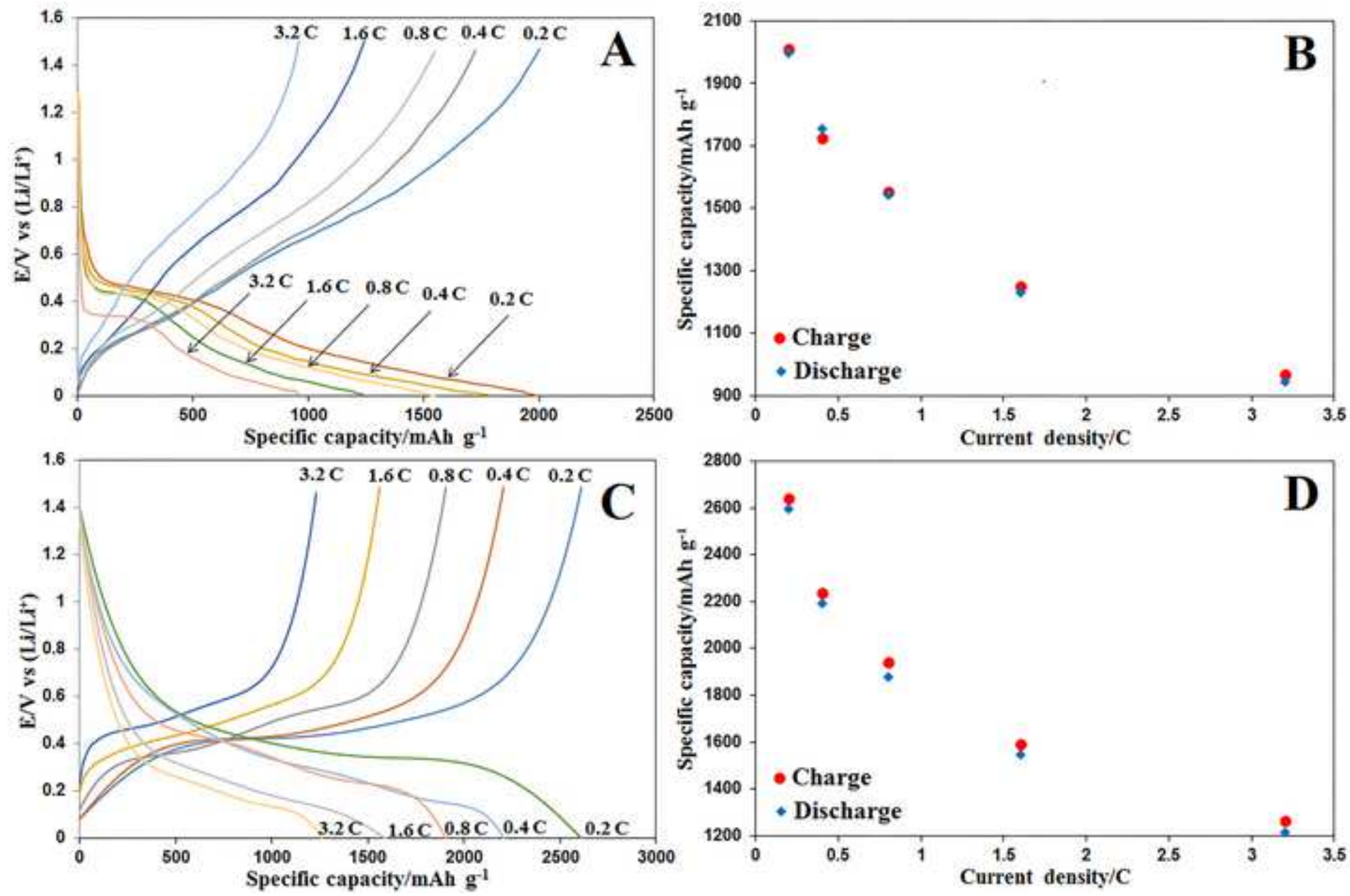

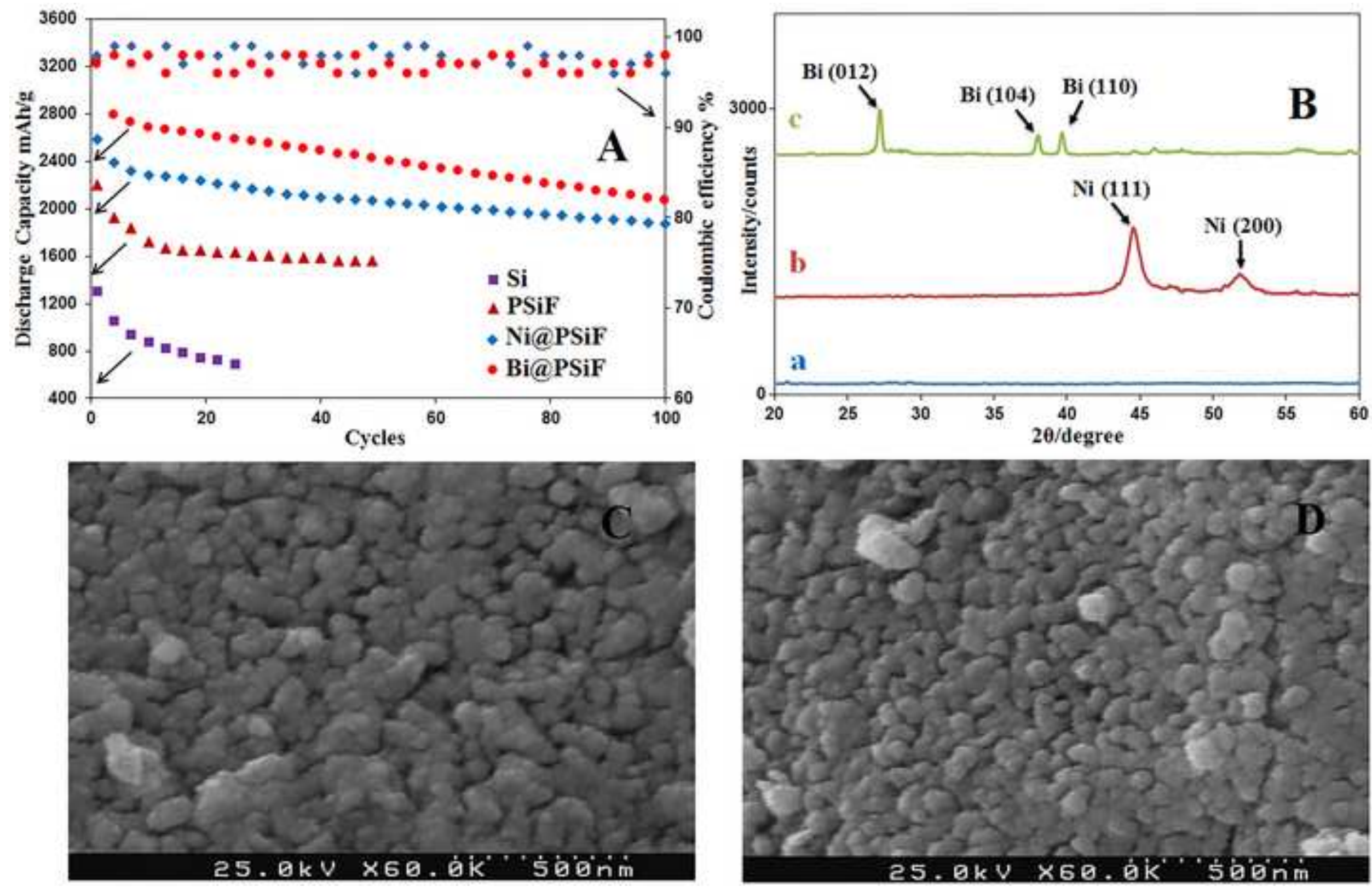